\title{
Bone mineral density and biochemical parameters of bone metabolism in female patients with systemic lupus erythematosus
}

Kurt Redlich, Sophie Ziegler, Hans P Kiener, Susanne Spitzauer, Petra Stohlawetz, Peter Bernecker, Franz Kainberger, Stephan Grampp, Stefan Kudlacek, Wolfgang Woloszczuk, Josef S Smolen, Peter Pietschmann

Department of Internal Medicine 3, Division of Rheumatology, University of Vienna, Austria

K Redlich

$S$ Ziegler

H P Kiener

P Stohlawetz

P Bernecker

J S Smolen

Division of Rheumatology and Institute of General and Experimental Pathology

P Pietschmann

Institute of Medical Chemistry and Laboratory

Diagnostics

S Spitzauer

Ludwig Boltzmann

Institute of

Experimental

Endocrinology

W Woloszczuk

Department of Radiology, Division of Osteoradiology,

Austria

F Kainberger

S Grampp

Krankenhaus der Barmherzigen Brüder, Department of Internal Medicine, Vienna, Austria

S Kudlacek

Correspondence to: Dr Pietschmann,

Department of Internal Medicine 3, Divison of Rheumatology, University of Vienna, Vienna General Hospital, Währinger Gürtel 18-20, A-1090 Vienna, Austria

Accepted for publication 10 December 1999

\begin{abstract}
Objective-To evaluate bone mineral density and biochemical parameters of bone metabolism in ambulatory premenopausal female patients with systemic lupus erythematosus (SLE).
\end{abstract}

Methods-30 women who fulfilled the ARA criteria for the classification of SLE were studied. Lumbar and femoral bone mineral density was determined by dual energy $x$ ray absorptiometry. Various laboratory parameters including serum calcium, serum phosphorus, alkaline phosphatase, bone specific isoform of alkaline phophatase, propeptide of type 1 procollagen, deoxypyridinoline excretion, telopeptide of type 1 collagen, serum creatinine, osteocalcin, parathyroid hormone, 25-OH vitamin $\mathrm{D}$, testosterone, progesterone, estradiol, follicle stimulating hormone and luteinotropic hormone were measured.

Results-According to the WHO criteria $39 \%$ of all patients with SLE studied had normal bone mineral density, $46 \%$ had osteopenia and $15 \%$ had osteoporosis at the lumbar spine; at the femoral neck $38.5 \%$ had normal bone mineral density, $38.5 \%$ had osteopenia and $23 \%$ suffered from osteoporosis. Significantly lower osteocalcin levels were found in SLE patients. All other bone resorption and formation markers measured were not statistically different, but higher serum albumin corrected calcium and lower phosphorus values were found in the SLE group. Of all sex hormones tested lower testosterone and higher follicle stimulating hormone concentrations were seen in patients with SLE.

Conclusion-A high incidence was found of osteopenia and osteoporosis in premenopausal patients with SLE. Bone diminution in SLE seems to be attributable, at least in part, to decreased bone formation in SLE patients.

(Ann Rheum Dis 2000;59:308-310)

Systemic lupus erythematosus (SLE) is a chronic inflammatory disease of unknown aetiology predominantly affecting women in their reproductive years. Many patients with SLE have to be treated with systemic glucocorticoids for prolonged periods of time. Moreover, active SLE is associated with menstrual irregularity and amenorrhoea.

Osteoporosis is defined as a systemic skeletal disease characterised by low bone mass and microarchitectural deterioration of bone tissue, with a consequent increase in bone fragility and susceptibility to fracture. ${ }^{1}$ Osteoporosis is a heterogenous disease of multifactorial origin. Among other factors, oestrogen deficiency and glucocorticoid treatment are associated with the development of osteoporosis.

In the past few years several biochemical markers of bone formation, like osteocalcin, the bone specific isoenzyme of alkaline phosphatase and the carboxy-terminal propeptide of type 1 procollagen (PICP) and bone resorption, like the urinary excretion of pyridinoline and deoxypyridinoline and the cross linked telopeptide of type 1 collagen (ICTP) have been described and successfully applied in clinical research.

The availability of dual energy $x$ ray bone absorptiometry constitutes another significant advance in the non-invasive assessment of patients with metabolic bone diseases. However, only few studies in the literature have considered the question, if patients with SLE have an increased incidence of osteopenia or osteoporosis. Kalla and coworkers described that SLE is associated with significant cortical bone loss. ${ }^{2}$ In contrast, Dhillon et al did not find a decreased lumbar bone mineral densisty (BMD) as assessed by dual energy $x$ ray absorptiometry. ${ }^{3}$ In a more recent study, Kalla and coworkers found that the BMD measured at the lumbar spine or the total femur is reduced $^{4}$; there were no significant differences between SLE patients treated with corticosteroids and those not receiving corticosteroids for six or more months before the start of the study.

In view of these descrepancies in the literature, the aim of this study was to determine the frequency of osteopenia in female patients with SLE. Moreover, as no data on newer biochemical parameters of bone metabolism in SLE have been published so far, various parameters of bone metabolism were determined in these patients.

\section{Methods}

Thirty women with SLE meeting the American Rheumatism Association's revised criteria for the classification of $\mathrm{SLE}^{5}$ under the age of 50 years were studied after giving informed consent. For every patient data were recorded 
Table 1 Clinical characteristics of the SLE patients studied. Data are mean (SEM)

\begin{tabular}{lcl}
\hline Age (y) & 33 & $(1.5)$ \\
Disease duration (months) & 79 & $(12)$ \\
Percentage of patients receiving & & \\
$\quad$ glucocorticoid treatment & 67 & $6.6(1.2)$ \\
Mean glucocorticoid dose (mg/d) & $14.6(3.5)$ \\
Cumulative glucocorticoid dose (g) & 10 \\
Percentage of patients with amenorrhoea & 10 \\
\hline
\end{tabular}

Table 2 Bone mineral density (BMD) in $\mathrm{g} / \mathrm{cm}^{2}, T$ scores and $Z$ scores of the SLE patients studied. Data are mean (SEM)

\begin{tabular}{|c|c|c|c|}
\hline & $B M D$ & $T$ scores & $Z$ scores \\
\hline $\begin{array}{l}\text { Lumbar } \\
\text { Femoral }\end{array}$ & $0.927(0.03)$ & $-1.09(0.26)$ & $-0.88(0.28)$ \\
\hline Neck & $0.754(0.03)$ & $-1.35(0.29)$ & $-1.15(0.33)$ \\
\hline Trochanter & $0.632(0.02)$ & $-1.01(0.27)$ & $-0.87(0.28)$ \\
\hline Intertrochanter & $0.968(0.03)$ & $-1.28(0.24)$ & $-1.20(0.29)$ \\
\hline Ward's triangle & $0.669(0.04)$ & $-1.16(0.34)$ & $-0.53(0.38)$ \\
\hline Total femur & $0.837(0.03)$ & $-1.15(0.25)$ & $-1.03(0.27)$ \\
\hline
\end{tabular}

on age, duration of disease, current medication, current glucocorticoid dose, cumulative glucocorticoid dose, menstrual history and SLE activity index scores (ECLAM, SIS).$^{67}$ The mean age was 33 years with a range from 18 to 48 years and the mean disease duration was 79 months with a range from 1 to 231 months. At the time of the study most SLE outpatients had only mild disease activity as indicated by SLE activity scores (mean (SEM): ECLAM: 3.3 (0.4), SIS: $6.2(0.7)$ ). The most frequent disease manifestations were nephritis, central nervous system involvement and haematological disorders.

Exclusion criteria for the SLE patients in this study were: any disease or condition known to affect bone not related to SLE or the treatment of SLE; the presence of lupus nephritis with serum creatinine concentrations exceeding the upper limit of the normal range; any medication known to affect bone metabolism with the exception of calcium and/or vitamin D supplements as well as glucocorticoids or other drugs specifically used for the treatment of SLE; any non-osteoporotic osseous disease; pregnancy.

Twenty four of the SLE patients $(80 \%)$ were treated with corticosteroid therapy. Among the latter 10 patients, $(33 \%)$ did not receive corticosteroids at the time of the study. Six patients $(20 \%$ of all patients studied) had never received corticosteroids. The mean glucocorti-

Table 3 Biochemical bone formation and resorption markers and sex hormones. Data are mean (SEM)

\begin{tabular}{|c|c|c|c|c|}
\hline \multirow[b]{2}{*}{ Albumin corrected serum calcium } & \multicolumn{2}{|l|}{ Controls } & $S L E$ & \multirow[t]{2}{*}{ Significance } \\
\hline & 2.06 & $(0.01)$ & $2.14(0.01)$ & \\
\hline Serum $P(\mathrm{mmol} / \mathrm{l})$ & 1.28 & $(0.04)$ & $1.12(0.04)$ & $\mathrm{p}=0.02$ \\
\hline Osteocalcin (ng/ml) & 20.5 & $(1.6)$ & $15.6(1.2)$ & $\mathrm{p}=0.03$ \\
\hline $25-\mathrm{OH}$ Vit $\mathrm{D}(\mathrm{ng} / \mathrm{ml})$ & 21.1 & $(1.7)$ & $27.7 \quad(2.9)$ & NS \\
\hline Alkaline phosphatase (U/1) & 91.0 & $(3.8)$ & $95.4 \quad(4.8)$ & NS \\
\hline $\begin{array}{l}\text { Bone specific isoenzyme of alkaline } \\
\text { phosphatase }(\mu \mathrm{g} / \mathrm{l})\end{array}$ & 10.0 & $(0.7)$ & $8.8(0.6)$ & NS \\
\hline PTH $(\mathrm{pg} / \mathrm{ml})$ & 28 & $(2.3)$ & $25 \quad(2.0)$ & NS \\
\hline $\operatorname{PICP}(\mu \mathrm{g} / 1)$ & 205 & (15) & (15) & NS \\
\hline Deoxypyridinoline excretion & & & & \\
\hline (nM/mM creatinine) & 8.0 & $(0.7)$ & $6.7 \quad(0.4)$ & NS \\
\hline $\begin{array}{l}\text { ICTP }(\mu \mathrm{g} / \mathrm{l}) \\
\text { Testosterone (ng/ml) }\end{array}$ & 0.38 & $(0.03)$ & $0.13(0.02)$ & $\mathrm{p}=0001$ \\
\hline $\mathrm{FSH}(\mathrm{mlU} / \mathrm{ml})$ & 11.0 & $(0.8)$ & $25.1 \quad(7.1)$ & $\mathrm{p}=0.42$ \\
\hline Estradiol (pg/ml) & 66.1 & $(7.4)$ & $65.5(10)$ & NS \\
\hline Progesterone $(\mathrm{ng} / \mathrm{ml})$ & 3.16 & (1.3) & $2.24(0.7)$ & NS \\
\hline $\mathrm{LH}(\mathrm{mlU} / \mathrm{ml})$ & 7.7 & $(0.8)$ & $13.5(2.9)$ & NS \\
\hline
\end{tabular}

coid dose/day (prednisolone equivalents) of all patients studied was $6.6 \mathrm{mg}$ with a maximum of $20 \mathrm{mg} /$ day and the cumulative glucocorticoid dose was $14.6 \mathrm{~g}$ with a maximum of $72 \mathrm{~g}$ (table 1).

Thirty nine healthy, age matched premenopausal women (medical students, health care workers and healthy blood donors from the same geographical area) were studied as a control group after giving informed consent. The age of the 39 controls was $32(0.1)$ years (mean $(\mathrm{SEM})$ ). Exclusion criteria were the same as for the SLE patients. In all control subjects routine blood chemistry was performed and found to be within the normal range.

In SLE patients BMD was measured by DXA (Hologic QDR 4500) and compared with a white, age and sex matched reference population given by the manufacturer.

Furthermore, serum concentrations of calcium, phosphorus, alkaline phosphatase, creatinine and albumin were determined by routine methods. The following parameters were measured by commercial radioimmunoassay (RIA) or enzyme linked immunoassay (ELISA): LH (ELISA, Genzyme, CA, USA), follicle stimulating hormone (FSH) (ELISA, Genzyme), estradiol (RIA, Sorin Diagnostics, Sallugia, Italy) progesterone (Progesterone RIA, Sorin Diagnostics), testosterone ( RIA, Sorin Diagnostics), parathyroid hormone (ELISA, CIS bio international, Cedex, France), 25 OH-vitamin D (RIA, Incstar Co, $\mathrm{MN}$, USA), osteocalcin (ELISA, CIS bio international), carboxyterminal PICP (RIA, Orion Diagnostica, Espoo, Finland), bone specific isoenzyme of alkaline phosphatase (RIA, Hybritech Inc, CA, USA) and cross linked ICTP (RIA, Orion Diagnostica). Second morning urine was tested for deoxypyridinoline excretion by using the Pyrilinks-D kit (ELISA) purchased from Metra Biosystems, Inc, Mountain View, CA. The data obtained in the SLE patients were compared with those of control subjects using non-parametric statistics (Wilcoxon-Mann-Whitney U test).

\section{Results}

There were 30 SLE outpatients eligible for study. Bone mass was measured at two sites. $T$ scores as well as $\mathrm{Z}$ scores at all sites measured were diminished compared with the above mentioned reference group (table 2). This was seen at both femoral and lumbar bone sites. According to the WHO criteria ${ }^{8} 39 \%$ of all patients with SLE studied had normal bone mineral density, $46 \%$ had osteopenia and 15\% had osteoporosis at the lumbar spine. At the femoral neck $38.5 \%$ had normal bone mineral density, $38.5 \%$ had osteopenia and 23\% suffered from osteoporosis. Of all markers for bone formation and resorption tested, only osteocalcin showed a significant difference between the SLE patients and the control group with lower levels in the SLE patients (table 3).

Albumin corrected serum calcium concentrations were slightly, but significantly increased in the SLE group, phosphorus values were found 
to be significantly lower in SLE patients but there were no significant differences in PTH or $25 \mathrm{OH}$ vitamin D levels (table 3).

In patients with SLE lower testosterone and higher FSH concentrations were seen. All other tested sex hormones (progesterone, LH, FSH, estradiol) were not significantly different (table 3).

To exclude effects of hypogonadism we compared all $(n=27)$ eugonadal SLE patients with healthy controls. Also in eugonadal SLE patients osteocalcin levels were significantly $(\mathrm{p}=0.03)$ lower than in healthy controls $(15.5$ (1.3) v 20.5 (1.6) $\mathrm{ng} / \mathrm{ml}$ ) and albumin corrected serum calcium concentrations were slightly, but significantly increased in the eugonadal SLE group, phosphorus values were found to be significantly lower in SLE patients (data not shown). Testosterone levels were significantly $(\mathrm{p}=0.0001)$ lower in eugonadal SLE patients $(0.13(0.02) v 0.38(0.03) \mathrm{ng} / \mathrm{ml})$. All other tested sex hormones (progesterone, LH, $\mathrm{FSH}$, estradiol) were not significantly different.

To evaluate possible corticosteroid effects we defined a subgroup of eugonadal SLE patients without actual glucocorticoid medication $(n=9)$ and compared it with healthy controls. These patients had also lower osteocalcin levels (14.7 (2) $v 20.5(1.6) \mathrm{ng} / \mathrm{ml})$ but only of borderline significance $(p=0.054)$. Serum testosterone concentrations were again significantly $(\mathrm{p}=0.001)$ lower in SLE patients $(0.18$ $(0.02) v 0.38(0.03) \mathrm{ng} / \mathrm{ml})$.

\section{Discussion}

The findings of this study show a high frequency of osteoporosis/osteopenia both at the lumbar spine and the femoral neck in premenopausal patients with SLE. These observations are in accordance with previous reports on white patients. ${ }^{3}$ Nevertheless, in Chinese patients a lower prevalence of osteoporosis has been described. ${ }^{9}$

The levels of osteocalcin, a parameter of bone formation, was significantly decreased in the SLE patients, two other bone formation parameters (bone specific isoenzyme of alkaline phosphatase and PICP) tended to be lower in the patients. Our data thus demonstrate that bone formation may be reduced, as suggested by slightly lower osteocalcin levels, although the other bone formation markers were not different. As in patients treated with glucocorticoids, decreased osteocalcin levels have been reported. ${ }^{10}$ It is possible that the low osteocalcin levels in some patients are related to current glucocorticoid treatment. On the other hand we observed low osteocalcin levels also in patients without current glucocorticoid treatment.

Serum testosterone concentrations were significantly decreased in the patients with SLE. This finding is in accordance with previous observations $^{11}$ and might be explained by increased testosterone oxidation at $\mathrm{C}-17 .^{12}$ Androgens play an important part in the regulation of bone turnover ${ }^{13}$; castrated men experience profound bone loss. ${ }^{14}$ In a recently published large population based study, Khosla et $a l^{15}$ found that serum testosterone rather than estradiol was an independent predictor of bone mineral density in premenopausal women. Thus low testosterone production may (perhaps as a cause of low bone formation) contribute to bone loss in patients with SLE.

Our results implicate several clinical consequences. Firstly, the high incidence of pathological bone mineral density measurements in young women with SLE justifies regular DXA screening of SLE patients. Secondly, osteocalcin determinations in patients with SLE seem to be superior to the other bone parameters studied. Thirdly, measures aimed at the prophylaxis and treatment of osteoporosis should be included in the medical management of patients with SLE. As testosterone and its derivatives may be involved in the reduced risk of men to develop autoimmune disease and as androgens may reduce SLE disease activity, investigations of hormonal therapy, such as those with DHEA, should also look into possible beneficial effects upon BMD.

Funding: this research was supported by: "MedizinischWissenschaftlicher Fonds des Bürgermeisters der Bundeshauptstadt Wien".

1 Consensus development conference: diagnosis, prophylaxis, and treatment of osteoporosis. Am J Med 1993;94:646-50.

2 Kalla AA, Meyers OL, Parkyn ND, Kotze TJ. Osteoporosis screening-radiogrammetry revisited. Br J Rheumatol 1989;
s. screening-ra

3 Dhillon VB, Davies MC, Hall ML, Round JM, Ell PJ, Jacobs HS, et al. Assessment of the effect of oral corticosteroids on bone mineral density in systemic lupus erythematosus: a preliminary study with dual energy $\mathrm{x}$ ray absorptiometry. Ann Rheum Dis 1990;49:624-6.

4 Kalla AA, Fataar AB, Jessop SJ, Bewerunge L. Loss of trabecular bone mineral density in systemic lupus erythematosus. Arthritis Rheum 1993;36:1726-34.

5 Tan EM, Cohen AS, Fries JF, Masi AT, McShane DJ, Rothfield NF, et al. The 1982 revised criteria for the classification of systemic lupus erythematosus. Arthritis Rheum 1982;25:1271-7.

6 Vitali C, Bencivelli W, Isenberg DA, Smolen JS, Snaith ML, Sciuto $M$, et al. Disease activity in systemic lupus erythematosus: report of the Consensus Study Group of the European Workshop for Rheumatology Research. II. and their use in the development of an activity score. The European Consensus Study Group for Disease Activity in SLE. Clin Exp Rheumatol 1992;10:541-7.

7 Smolen JS. Clinical and serological features of SLE. In: Smolen JS, Zielinsky CC. Systemic lupus erythematosus. Berlin: Springer-Verlag, 1987

8 Assessment of fracture risk and its application to screening for postmenopausal osteoporosis. Report of a WHO Study Group. World Health Organ Tech Rep Ser 1994;843:1129.

9 Li EK, Tam LS, Young RP, Ko GTC, Li M, Lau EMC. Loss of bone mineral density in chinese pre-menopausal women with systemic lupus erythematosus treated with corticosteroids. Br J Rheumatol 1998;37:405-10.

10 Peretz A, Praet JP, Bosson D, Rozenberg S, Bourdoux P. Serum osteocalcin in the assessment of corticosteroid induced osteoporosis. Effect of long and short term corticosteroid treatment. J Rheumatol 1989;16:363-7.

11 Jungers P, Nahoul K, Pelissier C, Dougados M, Tron F, Bach JF. Low plasma androgens in women with active or quiescent systemic lupus erythematosus. Arthritis Rheum 1982;25:454-7.

12 Lahita RG, Bradlow HL, Fishman J, Kunkel HG. Abnormal estrogen and androgen metabolism in the human with systemic lupus erythematosus. Am J Kidney Dis 1982;2:20611

13 Kapur SP, Reddi AH. Influence of testosterone and dihydrotestosterone on bone-matrix induced endochondral bone formation. Calcif Tissue Int 1989;44:108-13.

14 Stepan JJ, Lachman M, Zverina J, Pacovsky V, Baylink DJ. Castrated men exhibit bone loss: effect of calcitonin treatment on biochemical indices of bone remodeling. J Clin Endocrinol Metab 1989;69:523-7.

15 Khosla S, Melton LJ, Atkinson EJ, O'Fallon WM, Klee GG, Riggs BL. Relationship of serum sex steroid levels and bone
turnover markers with bone mineral density in men and turnover markers with bone mineral density in men and Endocrinol Metab 1998;83:2266-74. 